\title{
Effects of colocynth alkaloids and glycosides on Wistar rats fed high-fat diet. A biochemical and morphological study
}

\author{
Zahia Birem ${ }^{1}$, Khadidja Tabani ${ }^{1}$, Farid Lahfa ${ }^{2}$, Rabah Djaziri ${ }^{2}$, \\ Fatima Hadjbekkouche $^{3}$, el-Hadj Ahmed Koceir ${ }^{1}$, Naima Omari ${ }^{1}$
}

${ }^{1}$ Laboratory of Bioenergetics and Intermediary Metabolism, Department of Biology and Physiology of Organisms, El Alia, Bab-Ezzouar, Algiers, Algeria

${ }^{2}$ Laboratory of Physics and Chemistry, Synthesis and Biological Activities, Faculty of Nature, Life, the Earth, and the Universe, University of AbouBekrBelkaïd, Tlemcen, Algeria

${ }^{3}$ Laboratory of Endocrinology, Department of Biology and Physiology of Organisms, El Alia, Bab-Ezzouar, Algiers, Algeria

\begin{abstract}
Introduction. In traditional medicine, Citrullus colocynthis is used to treat diabetes, hyperlipidemia, cardiovascular diseases, inflammation, and oxidative stress, all of which can appear when a diet rich in vegetable fats, such as palm oil, is continuously consumed. Such high-fat diets are chronic stressors of the hypothalamic-pituitary-adrenal axis. The objective of our study was to analyze and evaluate the effects of colocynth total alkaloids and glycosides on metabolic, hormonal, and structural disorders of the adrenal medulla in Wistar rats fed a high-fat diet. Material and methods. Twenty six Wistar rats were distributed as follows: six control animals received a standard laboratory diet; twenty experimental rats received the standard laboratory diet supplemented with palm oil the high-fat diet (HFD). After seven months of this diet, the HFD group was subdivided into rats treated for the next 2 months with either alkaloid extract (HFD-ALk group) or ethanol extract of glycosides (HFD-GLc) or animals on HFD only. Plasma metabolites and ACTH concentrations were measured by standard methods. Sections of adrenal medulla were stained by Heidenhain-Azan method and Sudan Black.

Results. The adrenal medulla of the HFD rats showed prominent structural changes, such as hypertrophy of chromaffin and ganglion cells, vacuolation, inflammatory foci, and fibrosis. The biochemical and hormonal parameters were significantly improved in the HFD rats treated with alkaloid and glycoside extracts of Citrullus colocynthis. Moreover, the morphological changes of the adrenal medulla were attenuated in HFD-ALk and HFD-Glc rats.

Conclusions. The results of the study indicate that phytotherapy using Citrullus colocynthis alkaloids may correct metabolic and hormonal perturbations as well as adrenal medulla structure of rats maintained on HFD. (Folia Histochemica et Cytobiologica 2017, Vol. 55, No. 2, 74-85)
\end{abstract}

Key words: Citrullus colocynthis; alkaloids; glycosides; rat; high-fat diet; adrenal medulla; morphology; glucose; lipids; ACTH

Correspondence address: $\mathrm{Z}$. Birem

Laboratory of Bioenergetics and Intermediary Metabolism, Department of Biology and Physiology of Organisms

FSB, USTHB, BP32, El Alia, Bab-Ezzouar 16111 Algiers, Algeria

tel.: 0793861651 , fax: +213021 208518

e-mail: biremzahia@yahoo.fr

\section{Introduction}

Colocynth (Citrullus colocynthis) is a wild plant belonging to the Cucurbitaceae family. It is native to the arid, sandy desert of North Africa. Its aromatic seeds contain active substances, such as glycosides, alkaloids, saponins, flavonoids, and tannins [1,2]. 
Alkaloids generally possess anti-inflammatory activity by decreasing production of proinflammatory cytokines, such as IL-6, IL-1, and down-regulating the expression of COX-2, while simultaneously increasing expression of IL-4, an anti-inflammatory cytokine [3]. Like glycosides, alkaloids not only have hypoglycemic, lipid-lowering, antihypertensive, and antioxidant effects through the elimination of reactive oxygen species (ROS) [4,5] but also have negative effects on diabetes or antidiabetic effect $[6,7]$.

The antihyperglycemic activity of alkaloids and glycosides of Citrullus colocynthis is due to the restoration of the insulin secretion and the inhibition of intestinal glucose uptake [8].

Appropriate experimental models are essential tools for understanding the pathogenesis, complications, and genetic or environmental influences that increase the risks of type 2 diabetes. The animal models of type 2 diabetes can be obtained either spontaneously or induced by chemicals or dietary or surgical manipulations and/or by combination thereof. Experimental animals develop diabetes associated with obesity as a result of overnutrition as in diabesity syndrome of human population, and this usually requires long period of dietary treatment.

Since animals models of overnutrition are useful for testing of various therapeutic agents, we decided to assess the effects of the two Citrullus colocynthis extracts: the "glycosides" and the "alkaloids" fractions on the morphology of adrenal gland and metabolic and hormonal disorders in male Wistar rats maintained on "palm oil" rich high-fat diet (HFD). Palm oil itself is composed of 50\% palmitic acid and is suspected to have a hypercholesterolemic effect [9]. Its overconsumption results in such metabolic disorders as insulin resistance, type- 2 diabetes, cardiovascular diseases, and oxidative stress [10].

\section{Material and methods}

Animals. Male Wistar albino rats (Rattus norvegicus, $\mathrm{n}=26$ ) were chosen for this study. At the beginning of the experiment rats' mass was 147.5 to $153.7 \mathrm{~g}$. Rats were placed in individual plastic cages with a stainless steel lid and provided with feeding bottles; a thick layer of sawdust was placed on the bottom of the cages and was renewed every 3-4 days, or more often. The animal house was maintained at a temperature of $25 \pm 2^{\circ} \mathrm{C}$ with a humidity rate of $60 \%$ to $80 \%$ and a natural photoperiod. All experimental procedures were authorized by the Institutional Animal Care Committee of the National Administration of Algerian Higher Education and Scientific Research. Ethical approval number: law 98-11 of 22 August 1998.
Standard diet. The rats received daily food in the form of granules of commercial origin, provided by the national livestock feed office and water ad libitum. This balanced diet consisted of $23.03 \%$ protein, $9.00 \%$ fat, $48.00 \%$ carbohydrates, $3.00 \%$ vitamin-mineral complex, and $16.07 \%$ water.

Fat diet. Palm oil was extracted from the mesocarp of the oil palm fruit (Elaeisguineensis). Historically present in West Africa, oil palm is now grown in all tropical regions, especially in South East Asia. Raw palm oil contains a variety of antioxidant vitamins [11] necessary for the proper functioning of the body [12]. On the other hand, it is rich in saturated fatty acids, particularly stearic acid [12] and 45\% palmitic acid, which are the main risk factors in aggravating metabolic syndrome and cardiovascular diseases [13].

In our investigation, we used refined palm oil, in the form of solid fat, insoluble in water; its melting point is 38 to $40^{\circ} \mathrm{C}$. Palmitic acid, the principal constituent of refined palm oil increases low density lipoprotein cholesterol (LDL) in blood. Dietary quality norms recommend an average content of $39-47.5 \%$ of 16:0 (saturated palmitic acid) and $36-44 \%$ of $18: 1$ (mono-unsaturated oleic acid) for palm oil.

\section{Harvesting and extraction of total alkaloids from colocynth}

seeds. Harvesting of the mature fruits was done during September in Ain Sefra. The seeds of the dried fruits were collected and left to dry away from light; they were then ground. Alkaloids are compounds with a basic character. Their interaction with mineral acids (hydrochlorides, sulfates, and nitrates) or organic acids (tartrates, sulfamates, and maleates) results in the formation of salts. The extraction of these alkaloids depends, on one hand, on the degree of solubility in an acidic medium and alkaline medium; and on the other, on the polar or nonpolar organic solvents. Extraction in acidic medium was carried out according to Harborne [14] and Azzi et al. [2]: $90 \mathrm{~g}$ of colocynth was ground and degreased in $250 \mathrm{~mL}$ of $\mathrm{HCl}$ at $2 \%$ and $110 \mathrm{~mL}$ of ethyl acetate. The filtrate of the mixture was added to $\mathrm{NH}_{4} \mathrm{OH}$ at $10 \%$ and basic $\mathrm{pH}$. The filtrate mixture was then added to $50 \mathrm{~mL}$ of ethyl acetate, and filtrate liquid extraction was carried out 3 to 4 times with $50 \mathrm{~mL}$ of acetate until the aqueous phase alkaloids were completely depleted. The dry organic phase was concentrated using a rotavapor at ambient temperature to avoid denaturation of the alkaloids.

Extraction of glycosides from colocynth seeds. The extraction of the glycosides was carried out according to the method of Azzi et al. [2]; it involves mixing $200 \mathrm{~mL}$ of $80 \%$ ethanol with the same grounds for six hours. Ethanol contained in the filtrate in a water bath evaporates afterwards. The liquid extraction is carried out in four steps with $50 \mathrm{~mL}$ of ethyl acetate. Any traces of water were removed by the 
addition of $\mathrm{Na}_{2} \mathrm{SO}_{4}$. Dry mixing concentration was then carried using a rotavapor, as mentioned previously.

Experimental protocol. 26 male Wistar rats were randomly divided as follows: a control group $(n=6)$ received $30 \mathrm{~g}$ of standard laboratory food per day. They consumed about $93 \mathrm{kcal} /$ day. A second set of 20 experimental animals (E) were subjected to a standard high-fat diet, composed of $30 \mathrm{~g}$ of pellets supplemented with $8.16 \mathrm{~g}$ of palm oil. These animals consumed about $166.44 \mathrm{kcal} / \mathrm{day}$. After seven months on this diet, the HFD group was subdivided into rats maintained on HFD and treated for the next 2 months with Citrullus colocynthis extracts. The HFD-ALc group $(n=7)$ received a single intraperitoneal injection of $70 \mathrm{mg}$ of total alkaloid extract (ALc) per kilogram of body weight whereas the HFD-GLc group $(n=5)$ received a single intraperitoneal injection of $70 \mathrm{mg}$ of ethanol extract of cucurbitacin glycosides per kg b.w. Eight rats did not receive Citrullus colocynthis extracts but were kept on high-fat diet $(n=8)$.

\section{Material sampling}

Blood collection. Control rats and rats fed a high-fat diet underwent weekly weighing and monthly blood sampling, and the treated HFD-ALc group and HFD-GLc group were treated similarly. Blood was drawn by puncture of the retro-orbital sinus after the animals had fasted from 9 to $11 \mathrm{am}$. Blood was collected in heparinized and EDTA tubes and centrifuged at $3000 \mathrm{rpm}$ for $15 \mathrm{~min}$. The recovered plasma was frozen at $-20^{\circ} \mathrm{C}$ for biochemical and hormonal assays.

Organ removal. Rats were anesthetized by i.p. injection of $25 \%$ urethane at a dose of $0.4 \mathrm{~mL} / 100 \mathrm{~g}$ b.w. and perfused in situ with a suitable fixative [16]. During autopsy, adrenal glands were removed and post-fixed for 2-3 days in Bouin fixative for a morphological study, while the sublimate Bouin solution and Ciaccio fluid [17] were used for the histochemical study. Then small blocks of tissue were washed, dehydrated and embedded in paraffin. Sections, each 2-3 $\mu \mathrm{m}$ thick, were stained with Heidenhain-Azan and Sudan Black [17]. Morphometry was performed on histological sections of the adrenal glands in control animals, experimental animals and in those treated with alkaloids and glycosides. The measurements were calculated by an ocular micrometer, graduated to one hundredth of a millimeter.

Biochemical assays. Plasma concentration of glucose was measured by the Trinder colorimetric enzymatic method [18]. Triacylglycerides were measured by the colorimetric enzymatic method of Kaplan et al. [19]. The total cholesterol assay was carried out using the colorimetric enzymatic method of Friedewald et al. [20]. The HDL-cholesterol assay employed the colorimetric enzymatic method [21]. The LDL-cholesterol concentration was determined with the formula of Friedewald et al. [20]:
LDL-cholesterol $=$ total cholesterol - HDL-cholesterol (triacylglycerides/5).

Plasma ACTH measurements. The ACTH assay was based on the sandwich method (2010 Elecsys ACTH kit; 03255760190, ACTH CalSet, Roche Diagnostics Mannheim, Germany). The Cobas E411 analyzer (Modular analytics E170, Roche Diagnostics Elecsys HBs Ag Package Insert, Mannheim, Germany) automatically calculates the analyte concentration of each sample.

Statistical analysis. For the statistical analysis of the obtained data we used Statistica software (Statsoft, Tulsa, OK, USA) with the results being expressed as means \pm standard error of the mean (SEM). The data were analyzed using the Mann-Whitney $U$-test and the Kruskal-Wallis one-way analysis of variance on ranks. The relationships between ACTH and triglycerides or HDL-cholesterol plasma concentrations was performed with the Pearson correlation test. $\mathrm{P}$ values less than 0.05 were considered significant.

\section{Results}

\section{Changes of body mass, metabolite and hormone levels of control rats and rats on high-fat diet}

The body mass of the control animals and of those under the high-fat regime was monitored by monthly weighing over the seven months of the experiment. The mass of control rats increased gradually over the 7 months and was $100 \%$ higher at the end of the experiment than at its beginning (Table 1).

The increase in body mass of rats fed HFD was more rapid since it was significantly higher as compared to the control animals in the following months starting from the second month of HFD. At the end of the experiment, the animals fed a high-fat diet showed weight increase of $113 \%$ as compared to the initial body mass (Table 1).

\section{Plasma concentrations of metabolites}

The changes in certain plasma biochemical parameters in the control and experimental rats were monitored by monthly assays for seven months.

The HFD rats showed a substantial variation in blood glucose as compared with the control animals. Hyperglycemia was the highest from the $3^{\text {rd }}$ to the $5^{\text {th }}$ month on high-fat regime and then plasma glucose levels declined (Table 1) being $122 \%$ of the initial value at the end of the experiment.

As expected, the HFD animals had higher plasma levels of triglycerides and total cholesterol than control rats (Table 1). HFD diet increased plasma triglycerides and total cholesterol concentrations (as compared with the control rats) already after one 
Table 1. Body mass and plasma concentrations of glucose, lipids and ACTH of control rats and rats kept on high-fat diet for seven months

\begin{tabular}{|c|c|c|c|c|c|c|c|c|}
\hline & \multicolumn{8}{|c|}{ Duration of experiment (months) } \\
\hline & 0 & 1 & 2 & 3 & 4 & 5 & 6 & 7 \\
\hline \multicolumn{9}{|c|}{ Rats fed normal diet (control group) } \\
\hline Body mass [g] & $147.5 \pm 11.22$ & $176.8 \pm 15.83$ & $216.8 \pm 14.23$ & $258.8 \pm 6.9$ & $266.3 \pm 11.97$ & $287.7 \pm 4.29$ & $291.2 \pm 6.54$ & $294.7 \pm 9.23$ \\
\hline Glucose $[\mathrm{g} / \mathrm{L}]$ & $0.84 \pm 0.2$ & $0.76 \pm 0.07$ & $0.72 \pm 0.04$ & $0.80 \pm 0.03$ & $0.88 \pm 0.04$ & $0.91 \pm 0.04$ & $0.97 \pm 0.02$ & $0.78 \pm 0.04$ \\
\hline Triacylglicerides $[\mathrm{g} / \mathrm{L}]$ & $0.53 \pm 0.03$ & $0.80 \pm 0.03$ & $0.59 \pm 0.05$ & $0.49 \pm 0.02$ & $0.50 \pm 0.04$ & $0.64 \pm 0.03$ & $0.58 \pm 0.11$ & $0.78 \pm 0.07$ \\
\hline Total cholesterol $[\mathrm{g} / \mathrm{L}]$ & $0.71 \pm 0.04$ & $0.79 \pm 0.04$ & $0.66 \pm 0.04$ & $0.75 \pm 0.03$ & $0.80 \pm 0.07$ & $0.74 \pm 0.05$ & $0.66 \pm 0.05$ & $0.77 \pm 0.07$ \\
\hline HDL-cholesterol $[\mathrm{g} / \mathrm{L}]$ & $0.49 \pm 0.03$ & $0.52 \pm 0.03$ & $0.43 \pm 0.04$ & $0.52 \pm 0.04$ & $0.58 \pm 0.05$ & $0.52 \pm 0.04$ & $0.50 \pm 0.02$ & $0.52 \pm 0.06$ \\
\hline LDL-cholesterol $[\mathrm{g} / \mathrm{L}]$ & $0.12 \pm 0.02$ & $0.11 \pm 0.02$ & $0.11 \pm 0.01$ & $0.13 \pm 0.02$ & $0.13 \pm 0.02$ & $0.10 \pm 0.02$ & $0.05 \pm 0.03$ & $0.09 \pm 0.02$ \\
\hline $\mathrm{ACTH}[\mathrm{pg} / \mathrm{mL}]$ & $39.58 \pm 2.78$ & $42.81 \pm 2.43$ & $42.16 \pm 1.77$ & $43.89 \pm 2.39$ & $45.47 \pm 2.56$ & $44.01 \pm 1.99$ & $46.22 \pm 2.81$ & $45.07 \pm 2.01$ \\
\hline \multicolumn{9}{|c|}{ Rats fed high-fat diet (HFD group) } \\
\hline Body mass $[\mathrm{g}]$ & $153.6 \pm 8.35$ & $206.9 \pm 8.08$ & $253.6 \pm 6.25^{\mathrm{a}}$ & $278.5 \pm 7.99$ & $\begin{array}{c}287.31 \pm \\
9.04^{\mathrm{a}}\end{array}$ & $316 \pm 6.79^{\mathrm{a}}$ & $313.5 \pm 6^{\mathrm{a}}$ & $\begin{array}{c}326.83 \pm \\
5.08^{\mathrm{b}}\end{array}$ \\
\hline Glucose $[\mathrm{g} / \mathrm{L}]$ & $0.95 \pm 0.9$ & $0.90 \pm 0.08$ & $1.57 \pm 0.20^{\mathrm{c}}$ & $1.59 \pm 0.10^{\mathrm{c}}$ & $2.17 \pm 0.19^{\mathrm{c}}$ & $1.18 \pm 0.13$ & $1.30 \pm 0.11$ & $1.16 \pm 0.06^{\mathrm{b}}$ \\
\hline Triacylglicerides $[\mathrm{g} / \mathrm{L}]$ & $0.52 \pm 0.03$ & $1.15 \pm 0.15^{\mathrm{c}}$ & $1.16 \pm 0.08^{\mathrm{c}}$ & $0.85 \pm 0.05^{\mathrm{c}}$ & $0.86 \pm 0.08^{\mathrm{b}}$ & $0.99 \pm 0.09^{\mathrm{a}}$ & $1.09 \pm 0.22^{\mathrm{a}}$ & $0.99 \pm 0.10$ \\
\hline Total cholesterol $[\mathrm{g} / \mathrm{L}]$ & $0.76 \pm 0.02$ & $1.24 \pm 0.09^{\mathrm{b}}$ & $1.12 \pm 0.05^{\mathrm{c}}$ & $1.15 \pm 0.12^{\mathrm{a}}$ & $1.00 \pm 0.05$ & $1.04 \pm 0.06^{\mathrm{c}}$ & $1.02 \pm 0.04^{\mathrm{b}}$ & $1.12 \pm 0.04^{\mathrm{b}}$ \\
\hline HDL-cholesterol $[\mathrm{g} / \mathrm{L}]$ & $0.62 \pm 0.03^{\mathrm{a}}$ & $0.80 \pm 0.07$ & $0.43 \pm 0.03$ & $0.38 \pm 0.05^{\mathrm{b}}$ & $0.30 \pm 0.01^{\mathrm{c}}$ & $0.27 \pm 0.01^{\mathrm{c}}$ & $0.28 \pm 0.01^{\mathrm{c}}$ & $0.30 \pm 0.02^{\mathrm{c}}$ \\
\hline LDL-cholesterol $[\mathrm{g} / \mathrm{L}]$ & $0.05 \pm 0.01$ & $0.29 \pm 0.08^{\mathrm{a}}$ & $0.52 \pm 0.04^{\mathrm{c}}$ & $0.67 \pm 0.07^{\mathrm{b}}$ & $0.55 \pm 0.05^{\mathrm{c}}$ & $0.50 \pm 0.03^{\mathrm{c}}$ & $0.50 \pm 0.03^{c}$ & $0.58 \pm 0.09^{\mathrm{c}}$ \\
\hline $\mathrm{ACTH}[\mathrm{pg} / \mathrm{mL}]$ & $39.58 \pm 2.78$ & $77.25 \pm 3.60^{\mathrm{b}}$ & $65.04 \pm 6.6^{\mathrm{a}}$ & $71.02 \pm 3.64^{b}$ & $62.75 \pm 4.75^{\mathrm{a}}$ & $69.95 \pm 8.62^{\mathrm{a}}$ & $89.83 \pm 9.13^{c}$ & $81.04 \pm 3.99^{\circ}$ \\
\hline
\end{tabular}

Data represent means \pm SEM. Statistically significant differences between rats kept on high-fat diet $($ HFD group, $n=20)$, and control rats $(C, n=6)$ fed standard laboratory food. Metabolites and ACTH were measured in blood plasma as described in Methods. ${ }^{\mathrm{a}} \mathrm{p}<0.05 ;{ }^{\mathrm{b}} \mathrm{p}<0.01$; ${ }^{\mathrm{c}} \mathrm{p}<0.001$ versus control rats at the corresponding time points (Mann-Whitney test).

month on the diet. At the end of the experiment plasma concentrations of TG and total cholesterol in the HFD group were $90 \%$ and $47 \%$ higher than at its beginning (Table 1). When compared with control animals, the plasma concentrations of HDL-cholesterol decreased in rats subjected to HFD starting from the $4^{\text {th }}$ month of the experiment (Table 1). By the end of the experiment the value was $52 \%$ lower than at its start. In rats fed the highfat diet already after one month the plasma levels of LDL-cholesterol were much higher than in control rats (Table 1$)$.

\section{Plasma hormone concentrations}

In control rats the ACTH plasma levels did not undergo any significant variations during the experiment. However, rats fed HFD showed increased concentrations of ACTH starting from the first month of diet (Table 1). By the end of the experiment plasma ACTH level was $202 \%$ higher than at its start.

We observed a strong positive correlation between $\mathrm{ACTH}$ and triglycerides plasma concentrations in the HFD rats after the first, third, and sixth month on high-fat diet (Table 2). We also recorded a strongly negative correlation between the ACTH and HDL- -cholesterol fraction in the HFD group during the sixth month (Table 2).

\section{Morphometry, histology and histochemistry of the adrenal medulla of the control rats and those subjected to the high-fat diet}

\section{Morphometry}

Although the thickness of the adrenal medulla of the HFD rats increased by $9.38 \%$, this increase was not significant in comparison with the control animals.

\section{Histology and histochemistry}

In the control animals, the medulla of the adrenal gland showed the presence of endocrine medullary cells arranged in the form of spherical or oval groups, with about 10 cells in each group, surrounded by the basement membrane; sinusoidal capillaries and collagen fibers passing through these groups (Figs. 1A, 1A1). There were two types of cells (Figs. 1A, 1A1), the first of which was present in the central part of the medulla in the form of small polyhedral cells with central nuclei with abundant euchromatin. The second type of cell was present in the periphery of the medulla and consisted of columnar cells 
Table 2. Correlation between plasma concentrations of ACTH and some biochemical parameters of rats kept on high-fat diet for seven months

\begin{tabular}{|l|c|c|c|c|c|c|c|c|c|}
\hline & \multicolumn{7}{|c|}{ Duration of experiment (months) } \\
\cline { 2 - 9 } & $\mathbf{0}$ & $\mathbf{1}$ & $\mathbf{2}$ & $\mathbf{3}$ & $\mathbf{4}$ & $\mathbf{5}$ & $\mathbf{6}$ & $\mathbf{7}$ \\
\cline { 2 - 9 } & \multicolumn{8}{|c|}{ Rats fed high-fat diet (HFD group) } \\
\hline $\begin{array}{l}\text { ACTH }[\mathrm{pg} / \mathrm{mL}] / \\
\text { /triacylglicerides }[\mathrm{g} / \mathrm{L}]\end{array}$ & +0.062 & $+0.469^{\mathrm{c}}$ & -0.0738 & $+0.451^{\mathrm{c}}$ & -0.106 & +0.141 & $+0.874^{\mathrm{c}}$ & -0.592 \\
\hline $\begin{array}{l}\text { ACTH }[\mathrm{pg} / \mathrm{mL}] / \\
\text { /HDL-cholesterol }[\mathrm{g} / \mathrm{L}]\end{array}$ & +0.059 & -0.237 & +0.327 & -0.064 & +0.196 & $-0.684^{\mathrm{a}}$ & $-0.888^{\mathrm{c}}$ & +0.549 \\
\hline
\end{tabular}

Data represent correlation coefficient (r). Statistically significant differences between ACTH and TG, ACTH and HDL-cholesterol of rats kept on high-fat diet (HFD group, $\mathrm{n}=20$ ), ${ }^{\mathrm{a}} \mathrm{p}<0.05,{ }^{\mathrm{b}} \mathrm{p}<0.01,{ }^{\mathrm{c}} \mathrm{p}<0.001$ (Pearson correlation test).

Table 3. Body mass and plasma concentrations of glucose, lipids and hormones of HFD rats treated with colocynth alkaloids or glycosides for 60 days

\begin{tabular}{|l|c|c|c|c|c|}
\hline & \multicolumn{5}{|c|}{ Time of treatment (days) } \\
\hline & $\mathbf{0}$ & $\mathbf{1 5}$ & $\mathbf{3 0}$ & $\mathbf{4 5}$ & $\mathbf{6 0}$ \\
\hline \multicolumn{7}{|c|}{ HFD rats treated with alkaloids (Alc group) } \\
\hline Body mass [g] & $330.4 \pm 6.15$ & $302.7 \pm 8.58$ & $271.1 \pm 6.36$ & $239.0 \pm 13.17^{\mathrm{a}, * * *}$ & $225.3 \pm 19.27^{* * *}$ \\
\hline Glucose [g/L] & $1.19 \pm 0.10$ & $1.26 \pm 0.20^{\mathrm{a}}$ & $1.05 \pm 0.05$ & $0.96 \pm 0.07$ & $1.45 \pm 0.05$ \\
\hline Triacylglicerydes [g/L] & $0.97 \pm 0.16$ & $0.76 \pm 0.17$ & $0.97 \pm 0.30$ & $0.49 \pm 0.05^{\mathrm{a}, *}$ & $0.37 \pm 0.04^{\mathrm{b}, * * *}$ \\
\hline Total cholesterol [g/L] & $1.06 \pm 0.05$ & $0.86 \pm 0.09$ & $0.81 \pm 0.05$ & $0.71 \pm 0.02^{\mathrm{a}, * *}$ & $0.83 \pm 0.06$ \\
\hline HDL-cholesterol [g/L] & $0.28 \pm 0.03$ & $0.28 \pm 0.02$ & $0.26 \pm 0.02$ & $0.46 \pm 0.11$ & $0.33 \pm 0.01^{\mathrm{a}}$ \\
\hline LDL-cholesterol [g/L] & $0.51 \pm 0.19$ & $0.43 \pm 0.06$ & $0.36 \pm 0.04$ & $0.16 \pm 0.11$ & $0.44 \pm 0.05$ \\
\hline ACTH [pg/mL] & $81.0 \pm 7.42$ & $81.04 \pm 7.41$ & $42.92 \pm 2.17^{\mathrm{b}, * *}$ & $69.56 \pm 2.70$ & $82.65 \pm 2.67^{\mathrm{a}}$ \\
\hline \multicolumn{7}{|c|}{ HFD rats treated with glycosides $(\mathbf{G l c}$ group) } \\
\hline Body mass [g] & $321.2 \pm 8.79$ & $291.4 \pm 11.57$ & $280 \pm 7.41$ & $279 \pm 11.55$ & $271.8 \pm 12.13^{*}$ \\
\hline Glucose [g/L] & $1.13 \pm 0.03$ & $0.95 \pm 0.05$ & $0.95 \pm 0.03^{\mathrm{a}}$ & $1.02 \pm 0.05$ & $1.13 \pm 0.08^{\mathrm{b}}$ \\
\hline Triacylglicerydes [g/L] & $1.01 \pm 0.11$ & $1.16 \pm 0.17$ & $0.98 \pm 0.14$ & $0.68 \pm 0.05$ & $0.9 \pm 0.1$ \\
\hline Total cholesterol [g/L] & $1.19 \pm 0.07$ & $0.92 \pm 0.06$ & $0.85 \pm 0.01$ & $0.78 \pm 0.02^{* *}$ & $0.86 \pm 0.04$ \\
\hline HDL-cholesterol [g/L] & $0.3 \pm 10.03$ & $0.23 \pm 0.02$ & $0.24 \pm 0.02$ & $0.27 \pm 0.01$ & $0.27 \pm 0.02$ \\
\hline LDL-cholesterol [g/L] & $0.67 \pm 0.04$ & $0.46 \pm 0.04$ & $0.42 \pm 0.02$ & $0.38 \pm 0.01^{* *}$ & $0.40 \pm 0.04$ \\
\hline ACTH [pg/mL] & $81.04 \pm 3.99$ & $83.42 \pm 4.37$ & $61.28 \pm 3.43^{*}$ & $64.27 \pm 2.00^{*}$ & $105.47 \pm 3.28^{*}$ \\
\hline
\end{tabular}

Data represent means \pm SEM. *,*****Denote statistically significant differences between rats kept on high-fat diet $($ HFD rats) before $($ time period $=0$ ) and during treatment with colocynth alkaloids or glycosides for $15,30,45$ or 60 days at a given time point: $p<0.05$, p $<0.01$, p $<0.001$, respectively (Kruskal-Wallis test). ${ }^{\text {a, b, }}$ Denote statistically significant differences between HFD rats treated with alkaloids $($ Alc group, $\mathrm{n}=7)$ and HFD rats treated with glycosides (Glc group, $\mathrm{n}=5$ ): $\mathrm{p}<0.05, \mathrm{p}<0.01, \mathrm{p}<0.001$, respectively (Mann-Whitney test).

with oval nuclei and euchromatin. The cellular cytoplasm in the cells of the central part of the medulla was strongly basophilic, whereas the cytoplasm of cells in the periphery of medulla was less basophilic (Fig. 1A1); we also noted the presence of the medullary central vein (Fig. 1A).

The topographical and histochemical staining of the adrenal medulla area in the HFD rats shows the disorganization and hypertrophy of the light and dark chromaffin cells; the sympathetic ganglion cells are rare and hypertrophic (Figs. 1B, 1B1), compared to those in the medulla of control animals (Figs. 1A, 1A1). All the chromaffin cells contained a large spherical nucleus (Fig. 1B) and expressed signs of hyperactivity.

Apart from that, these medullary proportions reveal the infiltration of leucocytes (Fig. 2A), as well as fibrils, including collagen fibers (Fig. 1B, 1B1). Infiltration of leukocytes reflects the presence of inflammatory foci. The medulla area of HFD animals also shows infiltration of sudanophilic cells (Fig. 2B), presenting the vacuolated cytoplasm of most of the 

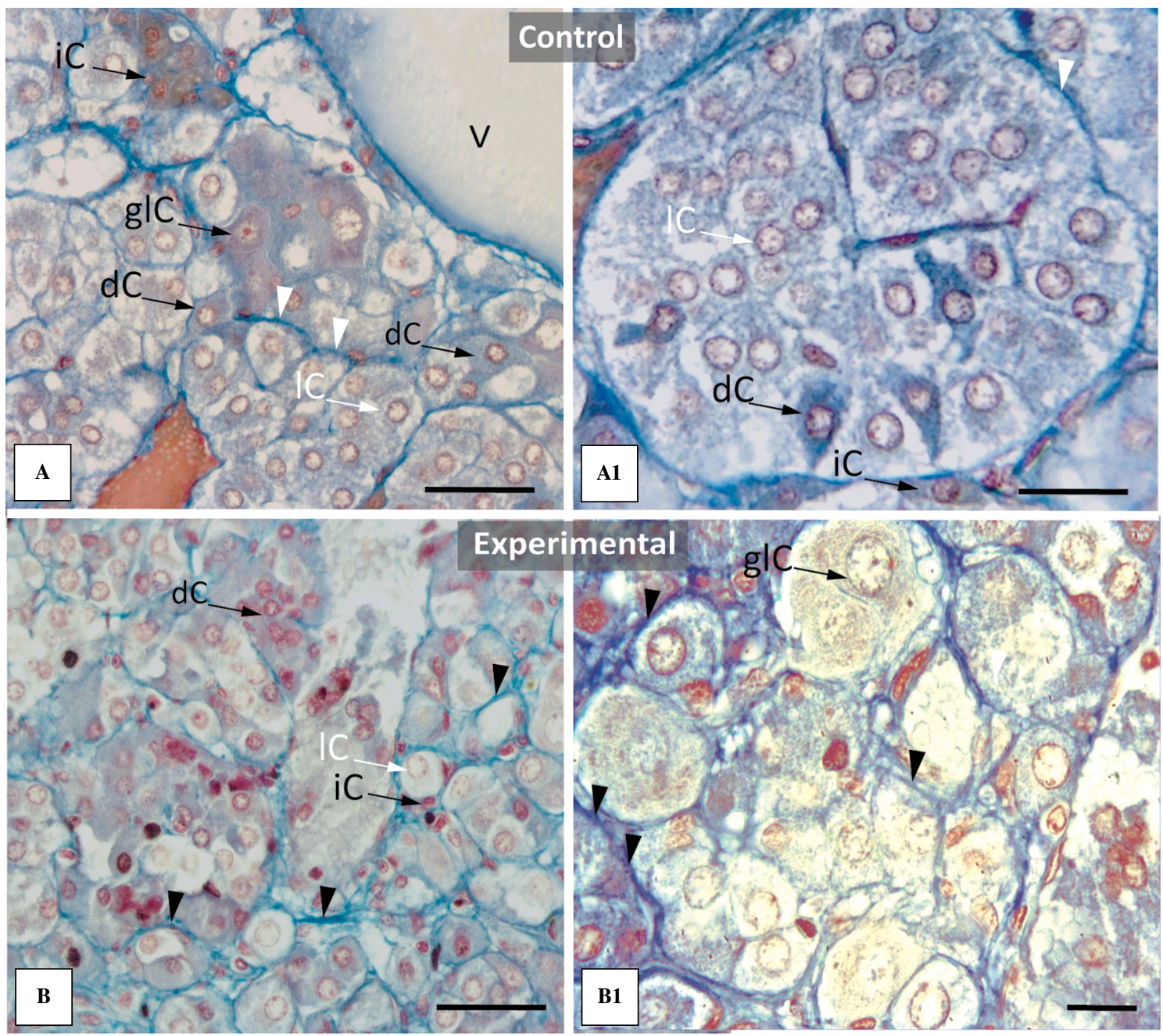

Figure 1. Heidenhain-Azan staining of the adrenal medulla of control rat and experimental rat (fed high-fat diet). A and A1. Control rat on a standard diet. White arrowheads show collagen fibers. Scale bars: (A) $250 \mu \mathrm{m}$, (A1) $10 \mu \mathrm{m} ; \mathbf{B}$ and B1. Rat fed a high-fat diet. Black arrowheads show infiltration of collagen fibers. Abbreviations: $\mathrm{dC}$ - dark cell; glC - ganglion sympathetic cell; V — central medullary vein; $1 \mathrm{C}$ — light cell; iC — interstitial cell. Scale bars: (A and B) - $250 \mu \mathrm{m}$, (A1 and B1) $-10 \mu \mathrm{m}$.

chromaffin cells (Fig. 2C) and significant accumulation of collagen fibers and fibroblasts (Fig. 2D).

\section{Changes of body mass, metabolite and hormone levels of rats subjected to the high-fat diet} and treated with colocynth alkaloids and glycosides

The body mass of HFD rats decreased significantly after 45 and 60 days of treatment with colocynth alkaloids (by $32 \%$ after 60 days). However, colocynth glycosides decreased body mass of HFD rats to a lesser extent, by $15.6 \%$, after 60 days of treatment (Table 3 ).

\section{Plasma concentrations of metabolites}

Blood glucose levels in the HFD rats treated with colocynth alkaloids showed a decrease by $11.8 \%$ at 30 days and by $19.3 \%$ at 45 days; however, this decrease was non-significant (Table 3). At 15 and 30 days, treatment with glycosides' extract did not significantly change the blood glucose concentrations in HFD rats (Table 3 ).

The administration of alkaloid extract of colocynth to HFD rats decreased plasma concentrations of triglycerides by $50 \%$ and $62 \%$ after 45 and 60 days of treatment (Table 3). However, administration of colocynth glycosides' extract to rats on HFD had generally no significant effect on plasma TG concentration.

The treatment of HFD rats with colocynth extracts tended to decrease plasma levels of total cholesterol; however, this effect was statistically significant only after 45 days of administration of alkaloids or glycosides (Table 3 ). Moreover, at day 45, cholesterolemia was significantly lower in HFD animals treated with 

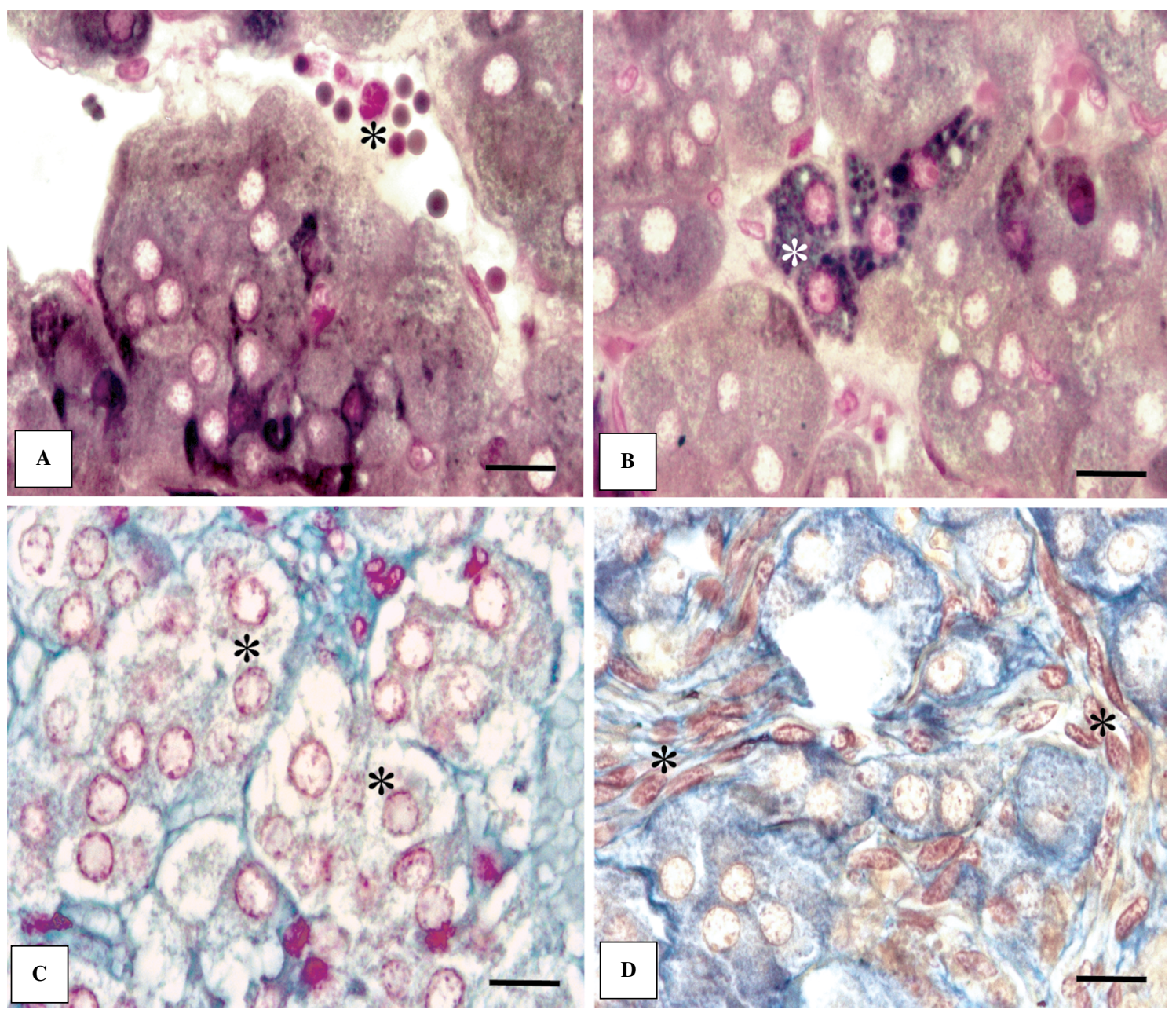

Figure 2. Sudan Black (A-B) and Heidenhain-Azan (C-D) staining of the adrenal medulla of control rat and experimental rat (fed high-fat diet). A. Leucocyte infiltration, monocytes and lymphocytes (black asterisk), HFD rat; B. Sudanophilic cell (white asterisk), HFD rat; C. Vacuolation (black asterisks), HFD rat; D. Signs of fibrosis (black asterisks), HFD rat. Scale bars: $10 \mu \mathrm{m}$.

colocynth alkaloids compared to those treated with glycosides (Table 3).

Plasma HDL-cholesterol levels of the HFD rats treated with colocynth alkaloids and glycosides showed small variations (Table 3). However, plasma LDL-cholesterol levels in HFD rats treated with glycosides showed a significant decrease by $43 \%$ after 45 days of treatment (Table 3 ). Colocynth alkaloids had no effect on plasma LDL-cholesterol concentrations in HFD rats (Table 3).

\section{Plasma ACTH concentrations}

After 30 days, the HFD rats treated with colocynth alkaloids showed a significant decrease in plasma levels of ACTH, by $47.04 \%$. After 30 days and 45 days, the HFD animals treated with glycosides showed a significant decrease in plasma levels of ACTH, by $24.38 \%$ and $20.69 \%$ respectively (Table 3 ). Further- more, at day 30 and 60, the plasma levels of ACTH was significantly lower in HFD animals treated with alkaloids compared to those treated with glycosides (Table 3).

\section{Morphometry, histology and histochemistry of the adrenal medulla of HFD rats treated with alkaloids and glycosides of Citrullus colocynthis}

\section{Morphometry}

The administration of alkaloid extract of Colocynth to HFD rats decreased the thickness of the adrenal medulla by $12.9 \%$ after 60 days of treatment; however, this decrease was not significant compared to that of HFD rats. On the contrary, the thickness of the adrenal medulla in HFD rats treated with glycosides showed a significant decrease by $21.6 \%$, after 60 days of treatment. 

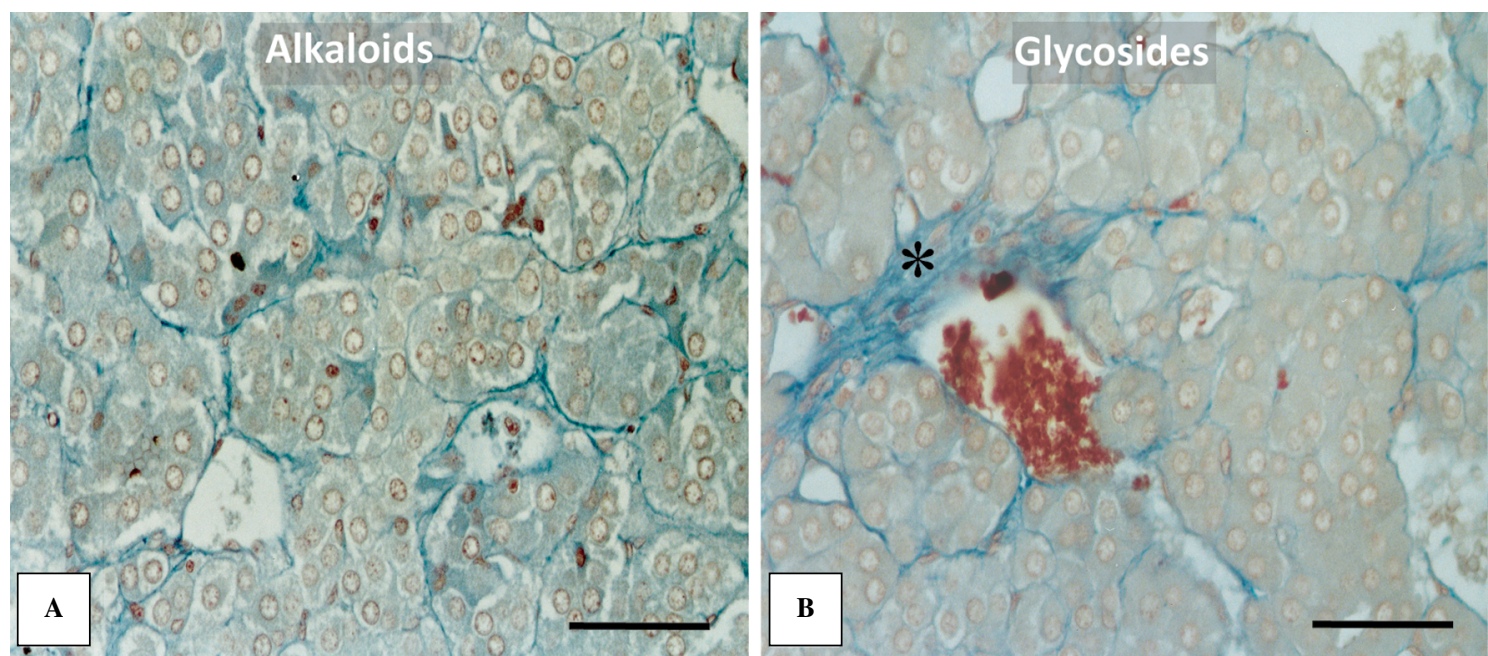

Figure 3. Heidenhain-Azan staining of the adrenal medulla of rats fed high-fat-diet treated with colocynth alkaloids or glycosides. A. Cords of chromaffin cells separated by blood sinusoids and collagen fibers; many cells have large rounded nuclei and granular cytoplasm (HFD rat treated with alkaloids); B. Irregularly-shaped chromaffin cells with granular cytoplasm, persistence of fibrosis (star) (HFD rat treated with glycosides). Scale bars: $250 \mu \mathrm{m}$.

\section{Histology and histochemistry}

Colocynth alkaloids treatment of HFD rats resulted in the reorganization of the medullary chromaffin cells' architecture (Fig. 3A). The cells were arranged in irregular small islets, with larger sizes. Most of the chromaffin cells showed normal euchromatic nuclei and dark granular cytoplasm, and we noted the absence of leucocytes infiltration, sudanophilic cells, vacuolation, and fibrosis (Fig. 3A).

In contrast, the colocynth glycosides treatment produced no apparent changes in the microarchitecture of the adrenal medulla. The cells are disorganized and hypertrophic. We also noted the presence of fibrosis (Fig. 3B).

\section{Discussion}

After this nine-month investigation, we analyzed the impact of "glycosides" and "alkaloids" — two cucurbitacin extracts of colocynth (Citrullus colocynthis) on adrenal gland and serum metabolite and ACTH levels in laboratory rats submitted to a standard diet enriched in palm oil.

The disturbances of lipid metabolism are hallmarks of metabolic syndrome in humans. In animals, various models have been applied to investigate the metabolic disturbances in obesity and atheromatosis: generally, they are based on dietary means of increasing lipid levels, commonly named as high-fat diets.

Changes in body mass are useful indications of the efficacy of experimental HFDs. Similarly to the findings of Ayeleso et al. [22], who subjected Wistar rats to the HFD for seven weeks, we also found a significant gain of body mass in our rats kept on palm-oil based HFD.

The treatment with the two colocynth extracts shows that the alkaloids were found to significantly suppress increases in body mass, showing potential for anti-obesity actions. This effect recalls that of Azzi et al. [2] who observed a decrease in body weight in rats made diabetic with streptozotocin and treated with colocynth alkaloids for three weeks. This weight regression can be explained by the alkaloids' anorexigenic effect [23]. The anti-obesity actions of purslane ethanolic extract may be due to the reduction of insulin resistance and atherogenic index [24]. Adeneye and Crooks [25] showed that alkaloid fraction of $H$. umbellata caused significant weight loss in the treated rats what suggests that alkaloid fraction of H. umbellata may have anti-obesity effect.

\section{Plasma biochemical parameters in control and $H F D$ rats and in the HFD rats treated with colocynth alkaloids and glycosides for 8 weeks}

Glycaemic status. We found that the palm-oil-rich diet caused hyperglycemia similarly to the effect of lipid-enriched diet fed to rats for 25 weeks [26].

Treatment with alkaloid and glycoside extracts for eight weeks did not change blood glucose concentration in HFD rats. On the other hand, Abdel-Hassan et al. [4] showed that the C. colocynthis extract had a hypoglycemic effect in rabbit and they attributed this effect to the glycosidic components present in this plant [4]. It has been stated that the anti-diabetic action of $C$. colocynthis is probably due to enhanced 
insulin secretion, decreased gluconeogenesis, and inhibition of the release of counter-regulatory hormones including cortisol, glucagon, and growth hormone [27].

Lipid status. Hypertriglyceridemia was commonly observed in rats on high-fat diet [28]. We found that colocynth alkaloids, but not glycosides, decreased triglyceride plasma levels in HFD rats. This is consistent with the work of Cao et al. [29], who reported reduction of plasma triglyceride levels in rats fed a high-fat diet and treated with alkaloids of Rhizoma coptidis. Adeneye and Crooks [25] showed a reduction in serum TG in triton-induced hyperlipidemic rat treated with alkaloid fraction of $H$. umbellata for 14 days. This action of alkaloids may be due to the increased catabolism of liver lipoproteins [30].

The hypercholesterolemia in rats on atherogenic diets was reported by many authors [31]. Interestingly, the elevated plasma cholesterol levels decreased significantly following treatment of HFD rats with colocynth alkaloids. These results recall those of Cao et al. [29] who found a decrease in cholesterol serum level in rats treated with alkaloids of Rhizoma coptidis. Similarly, Adeneye and Crooks [25] reported a decrease in cholesterol in triton-induced hyperlipidemic rat treated with alkaloid fraction of $H$. umbellata for 14 days. According to these authors, alkaloid fraction of $H$. umbellata mediates its antihyperlipidemic effect via inhibition of cholesterol biosynthesis. The return to normal values may be related to the inhibition of hepatic cholesterol biosynthesis and increased plasma lecithin-cholesterol acyltransferase activity [32]. In contrast to the alkaloids the colocynth glycosides did not decrease plasma total cholesterol concentrations in HFD rats. Furostenol glycoside from Trigonella foenum-graecum seeds, and especially diosgenin, had various effects on cholesterol metabolism, including decrease in plasma cholesterol concentration in hypercholesterolemic animals [33].

Plasma HDL-cholesterol levels, thought to have a cardioprotective activity, were significantly decreased in rats fed a high-fat diet. Bais et al. [34] showed a decrease in HDL-c in rats subjected to hyperlipidic diet for 49 days. However, neither colocynth alkaloids nor glycosides significantly changed plasma HDL-c levels, similarly to the reports by Ibekwe et al. [35] and Subramani et al. [36]. The observed highly significant increase in LDL-cholesterol plasma levels in rats on HFD is in agreement with other studies [36]. Treatment with the colocynth glycosides decreased plasma LDL-cholesterol levels. This decline may be explained by decreased cholesterol absorption in the intestines or induction of LDL receptors within the peripheral tissue [37]. Citrullus colocynthis contains many active substances such as saponins, alkaloids, and glycosides, and it is used as antidiabetic and antioxidant $[4,5]$. The decrease in LDL-cholesterol may be related to anti-oxidant effect of glycosides. As a member of polyphenols, flavonoid glycoside could regulate lipid metabolism by suppressing progression of atherosclerosis [38].

Joshi et al. showed that Amomum subulatum has antioxidant effects and decreases serum LDL-cholesterol and TG levels without any side effects [39]. Previous studies claimed that phenolic compounds could reduce the hyperlipidemia. Kapoor et al. showed that seeds of $A$. subulatum contain glycosides, petunidin-3,5-diglucoside, eucocyanidin-3-O- $\beta$-D-glucopyranoside, subulin (new aurone glycoside) and 1-8, cineole, $\alpha$-terpinyl acetate [40].

\section{Hormonal status}

We noted a highly significant increase in ACTH plasma concentration in rats fed the high-fat diet. This finding corroborates the work of Mokrani et al. [41] who reported an increase in ACTH plasma levels in rabbits on a high-fat diet. The strong correlation between ACTH and triglyceridemia in our HFD rats was also found in obese humans by Prodam et al.[42] who suggested that it may be due to insulin resistance. We found also a correlation between the ACTH and HDL-cholesterol levels in the HFD rats. This agrees with the results of Whitworth et al. [43], who reported a close association between Cushing's syndrome and decreased serum HDL-cholesterol level. Interestingly, we found that the increased high plasma ACTH levels of HFD rats were decreased by treatment with colocynth alkaloids. This improvement may be due to kalirin, which restores the regulation of ACTH secretion inhibited by the high expression of peptidylglycine $\alpha$-amidating monooxygenase enzyme [44].

\section{Effects of high-fat diet and Citrullus colocynthis alkaloids and glycosides on rat adrenal medulla morphology}

We did not find significant changes in the thickness of adrenal medulla in HFD rats. On the contrary, Mokrani et al. [41] reported a significant increase in the thickness of adrenal medulla in rabbits fed HFD for 15 weeks. Similarly, Omari et al. [45] showed that in white rats made diabetic with streptozotocin, the thickness of the adrenal medulla did not vary significantly from that of the control animals. However, the thickness of the adrenal medulla decreased in diabetic Wistar BB rats [46], in long-term diabetes [47] and in sand rats Psammomys obesus made diabetic and obese by nutritional stress [48]. 
In the present study we found that the adrenal medulla was composed of irregular epithelioid cells arranged in rounded groups or short cords and mostly columnar or polyhedral chromaffin cells separated by sinusoids, similarly as in African giant rat [49]. Our observation of the disruption of adrenal medulla structure and hypertrophy of light and dark chromaffin cells in rats kept on HFD corresponds to the finding of chromaffin cell degeneration and sympathetic ganglion cell hypertrophy in diabetic rats [50]. Moreover, in our study the adrenal medulla of HFD rats showed the infiltration of leucocytes which was also observed in diabetic rats [50]. This local inflammation might have been caused by the activity of free radicals such as superoxide, hydroxyl anion and hydrogen peroxide released from macrophages and neutrophils [51] that damage structure of lipids, proteins, carbohydrates and nucleic acids [52]. In the sections of the adrenal medulla of the HFD rats we observed vacuolated cytoplasm of the chromaffin cells. The cytoplasmic vacuolation, mitochondrial degeneration, and decreased number of secretory granules were found in the cells of adrenal medulla of nicotine-treated mice [53]. Sanaa et al. showed a vacuolation of germinal epithelium of seminiferous tubules section in testes of rats treated with high-fat diet [54].

We observed fibrosis in the adrenal medulla of rats fed high-fat diet. These observations recall those of Mokrani et al. [41] who found the same phenomena in rabbits fed a high-calorie diet for 15 weeks. Moreover, a remodeling of the extracellular matrix and scar fibrosis was observed by us in HFD rats. It might have been caused by the presence of chronic inflammation [55].

The sudanophilia found in the same area in our animals is similar to that observed by Omari et al. who worked on deserticolous rodents (sand rats) and diabetic rats [45]. In our study, the structure of adrenal medulla of the HFD rats treated with colocynth extracts reversed to normal. The treatment of HFD rats with alkaloids, rather than glycosides, dramatically corrected medulla's architecture since the shape and size of the chromaffin cells almost returned to normal. Hekmat and Sannaa reported that cellular changes in the adrenal medulla induced by nicotine were attenuated by curcumin [53]. Such tissue reorganization may be due to radical scavenging and antioxidant activities of powerful alkaloids that inhibit lipid peroxidation [56]. The disappearance of leukocyte infiltration in HFD rats caused by colocynth alkaloids treatment observed in our study suggests that they exert an anti-inflammatory effect within the adrenal medulla. Moreover, intense vacuolation and fibrosis also disappeared during colocynth alkaloids treatment. These observations agree with those of Marzouk et al. who subjected Wistar rats to phytotherapy based on alkaloids, steroids, flavonoids, and colocynths present in fruits and seeds [3].

\section{Conclusions}

This study shows that the high-fat diet based on palm oil enrichment results in white male rats in biochemical and hormonal disorders as well as in the changes of adrenal medulla's microarchitecture. Since the elevated plasma cholesterol and LDL-cholesterol levels decreased significantly following treatment of HFD rats with colocynth alkaloids the anti-atherogenic activity of Citrullus colocynthis alkaloids may be used as a supportive therapy against atheromatosis.

\section{References}

1. Diwan FH, Abdel-Hassan IA, Mohammed ST. Effect of saponin on mortality and histopathological changes in mice. East Mediterr Health J. 2000; 6(2-3): 345-351, indexed in Pubmed: 11556022.

2. Azzi R, Djaziri R, Lahfa F. Recherche des effets anti-hyperglycémiants des glycosides cucurbitacines extraits des graines de coloquinte (Cirtrullus colocynthis) sur des rats Wistar normaux et rendus diabétiques par la Streptozotocine. Subst Nat Innov Therap. 2009; 1: 50-52.

3. Marzouk B, Marzouk Z, Haloui E, et al. Anti-inflammatory evaluation of immature fruit and seed aqueous extracts from several populations of Tunisian Citrullus colocynthis Schrad. Afr J Biotechnol. 2011; 10: 4217-4225, doi: 10.5897/ /AJB10.2181.

4. Abdel-Hassan IA, Abdel-Barry JA, Tariq Mohammeda S. The hypoglycaemic and antihyperglycaemic effect of citrullus colocynthis fruit aqueous extract in normal and alloxan diabetic rabbits. J Ethnopharmacol. 2000; 71(1-2): 325-330, doi: 10.1016/s0378-8741(99)00215-9, indexed in Pubmed: 10904181.

5. Gebhardt R. Antioxidative, antiproliferative and biochemical effects in HepG2 cells of a homeopathic remedy and its constituent plant tinctures tested separately or in combination. Arzneimittelforschung. 2003; 53(12): 823-830, doi: 10.1055/s0031-1299836, indexed in Pubmed: 14732962.

6. Rahbar AR, Nabipour I. The hypolipidemic effect of Citrullus colocynthis on patients with hyperlipidemia. Pak J Biol Sci. 2010; 13(24): 1202-1207, doi: 10.3923/pjbs.2010.1202.1207, indexed in Pubmed: 21313901.

7. Sukandar EY, Permana H, Adnyana IK, et al. Clinical Study of Turmeric (Curcuma longa L.) and Garlic (Allium sativum L.) Extracts as Antihyperglycemic and Antihyperlipidemic Agent in Type-2 Diabetes-Dyslipidemia Patients. International Journal of Pharmacology. 2010; 6(4): 456-463, doi: 10.3923/ /ijp.2010.456.463.

8. Patel DK, Prasad SK, Kumar R, et al. An overview on antidiabetic medicinal plants having insulin mimetic property. Asian Pac J Trop Biomed. 2012; 2(4): 320-330, doi: 10.1016/S2221-1691(12)60032-X, indexed in Pubmed: 23569923.

9. Godswill N, Tsomboh- N, Likeng-Li-Ngue B, et al. Effects of dietary fatty acids on human health: Focus on palm oil from Elaeis guineensis Jacq and useful recommendations. Food Public Health. 2016; 6: 5-85, doi: 10.5923/j.fph.20160603.03.

10. Kochikuzhyil BM, Devi K, Fattepur SR. Effect of saturated fatty acid-rich dietary vegetable oils on lipid profile, antioxidant enzymes and glucose tolerance in diabetic rats. Indian J Pharmacol. 2010; 42(3): 142-145, doi: 10.4103/0253-7613.66835, indexed in Pubmed: 20871763. 
11. Bayorh MA, Abukhalaf IK, Ganafa AA. Effect of palm oil on blood pressure, endothelial function and oxidative stress. Asia Pac J Clin Nutr. 2005; 14(4): 325-339, indexed in Pubmed: 16326639.

12. Dauqan E, Sani HA, Abdullah A, et al. Effect of different vegetable oils (red palm olein, palm olein, corn oil and coconut oil) on lipid profile in rat. Food Nutr Sci. 2011; 2: 253-258, doi: 10.4236/fns.2011.24036.

13. Mancini A, Imperlini E, Nigro E, et al. Biological and Nutritional Properties of Palm Oil and Palmitic Acid: Effects on Health. Molecules. 2015; 20(9): 17339-17361, doi: 10.3390/ /molecules200917339, indexed in Pubmed: 26393565.

14. Harborne JB. Phytochemical Methods: A Guide to Modern Techniques of Plant Analysis. Third ed. Chapman and Hall Thomson Science (UK). 1998: 203-234.

15. Paris M, Hurabielle M. Abrégé de Matière médicale (Pharmacognosie). Vol. 1. Masson, Paris 1981: 256-266.

16. Baleydier CJ. Microscopie. 1973; 17(33).

17. Gabe M. Techniques histologiques. Masson, Paris 1968.

18. Trinder P. Determination of glucose in blood using glucose oxydase with an alternative oxygen acceptor. Ann Clin Biochem. 1969; 6(1): 24-27, doi: 10.1177/000456326900600108.

19. Kaplan LA, Rubaltelli FF, Hammerman C, Vilei MT, Leiter C, Abramov A. Triglycerides. In: Kaplan LA, Pesce AJ. ed. Clinical Chemistry: Theory, Analysis and Correlation. Mosby Co., St Louis, Toronto, Princeton 1984.

20. Friedewald WT, Levy RI, Fredrickson DS. Estimation of the concentration of low-density lipoprotein cholesterol in plasma, without use of the preparative ultracentrifuge. Clin Chem. 1972; 18(6): 499-502, indexed in Pubmed: 4337382.

21. Naito HK. High-density lipoprotein (HDL) cholesterol. In: Kaplan LA, Pesce AJ. ed. Clinical Chemistry: Theory, Analysis and Correlation. Mosby Co, St Louis, Toronto, Princeton 1984: 1207-1213.

22. Ayeleso AO, Oguntibeju OO, Brooks NL. Effects of dietary intake of red palm oil on fatty acid composition and lipid profiles in male Wistar rats. Afr J Biotechnol. 2012; 33: 8275-8279, doi: 10.5897/AJB11.4080.

23. Golay A. Metformin and body weight. Int J Obes (Lond). 2008; 32(1): 61-72, doi: 10.1038/sj.ijo.0803695, indexed in Pubmed: 17653063.

24. Abdalla HM. Purslane extract effects on obesity-induced diabetic rats fed a high-fat diet. Malays J Nutr. 2010; 16(3): 419-429, indexed in Pubmed: 22691995.

25. Adeneye A, Crooks P. Weight losing, antihyperlipidemic and cardioprotective effects of the alkaloid fraction of Hunteria umbellata seed extract on normal and triton-induced hyperlipidemic rats. Asian Pac J Trop Biomed. 2015; 5(5): 387-394, doi: 10.1016/s2221-1691(15)30374-9.

26. Ezzat-Ali Esmail O. A Possible protective effect of Citrullus colocynthis melon against diabetes mellitus type-2 associated with non-alcoholic fatty liver syndrome in rats. J Am Sci. 2012; 8: 1054-1061.

27. Abdel-Baky A, Abdulla A, Abdel-Mawgoud H, et al. Hypoglycemic and hypolipidemic action of bitter melon on normoglycemic and hyperglycemic diabetic rats. Res J Med Med Sci. 2009; 4: 519-525.

28. Storlien LH, Higgins JA, Thomas TC, et al. Diet composition and insulin action in animal models. Br J Nutr. 2000; 83(Suppl 1): S85-S90, indexed in Pubmed: 10889797.

29. Cao Y, Bei W, Hu Y, et al. Hypocholesterolemia of Rhizoma Coptidis alkaloids is related to the bile acid by up-regulated CYP7A1 in hyperlipidemic rats. Phytomedicine. 2012; 19(8-9): 686-692, doi: 10.1016/j.phymed.2012.03.011, indexed in Pubmed: 22554715.
30. Li Z, Berk M, McIntyre TM, et al. The lysosomal-mitochondrial axis in free fatty acid-induced hepatic lipotoxicity. Hepatology. 2008; 47(5): 1495-1503, doi: 10.1002/hep.22183, indexed in Pubmed: 18220271.

31. Go RE, Hwang KA, Kim YS, et al. Effects of palm and sunflower oils on serum cholesterol and fatty liver in rats. J Med Food. 2015; 18(3): 363-369, doi: 10.1089/jmf.2014.3163, indexed in Pubmed: 25393932.

32. Wansi SL, Fodoup SFK, Nyadjeu P, et al. Antioxydative and antihypertensive effects of the aqueous leaf of Gmelina arborea on rats fed with high sodium chloride diet. Pharmacology online. 2009; 2: 750-762.

33. Raju J, Rao CV. Diosgenin, a steroid saponin constituent of yams and fenugreek: emerging evidence for applications in medicine. In: Rasooli I. ed. Bioactive compounds in phytomedicine. InTech Publishers, Rijeka, Croatia 2012: 125-142.

34. Bais S, Singh G, Sharma R. Antiobesity and Hypolipidemic Activity ofMoringa oleiferaLeaves against High Fat Diet-Induced Obesity in Rats. Adv Biol. 2014: 1-9, doi: 10.1155/2014/162914.

35. Ibekwe HA, Adinya IB, Onyeama HP, et al. Diet and alkaloid extract of Garcinia Kola induce reduction in serum levels of selected indices of coronary heart disease and liver functions. Afr J Food Sci. Technol. 2013; 4: 80-83.

36. Subramani C, Rajakkannu A, Rathinam A, et al. Anti-atherosclerotic activity of root bark of Premna integrifolia Linn. in high fat diet induced atherosclerosis model rats. J Pharmaceut Anal. 2017; 7(2): 123-128, doi: 10.1016/j.jpha.2016.12.002.

37. Ahmed M, Alierza G, Mahboobeh V. Hypocholesterolemic effects of purslane extract on serum lipids in rabbits fed with high cholesterol levels. Int J Pharmacol. 2007; 3: 285-289.

38. Zhai X, Chi J, Tang W, et al. Yellow wine polyphenolic compounds inhibit matrix metalloproteinase-2, -9 expression and improve atherosclerotic plaque in LDL-receptor-knockout mice. J Pharmacol Sci. 2014; 125(2): 132-141, indexed in Pubmed: 24859779.

39. Joshi SC, Bairwa GL, Sharma N. Effect of Amomum subulatum on oxidative stress and serum lipids in cholesterol fed rabbits. Int J Nat Prod Res. 2012; 1: 1-6.

40. Kapoor IPS, Singh B, Singh G, et al. Chemistry, antifungal and antioxidant activities of cardamom (Amomum subulatum) essential oil and oleoresins. Int J Essential Oil Therap. 2008; 2: 29-40.

41. Mokrani Z, Soltani Y, HadjBekkouche F. Visceral obesity induced by a high-calorie diet leads to dyslipidemia, insulin resistance and impairs adrenal function in male rabbits. Pathol Hygiene. 2012: 1213-1218.

42. Prodam F, Ricotti R, Agarla V, et al. High-end normal adrenocorticotropic hormone and cortisol levels are associated with specific cardiovascular risk factors in pediatric obesity: a cross-sectional study. BMC Med. 2013; 11: 44, doi: 10.1186/1741-7015-11-44, indexed in Pubmed: 23425018.

43. Whitworth JA, Williamson PM, Mangos G, et al. Cardiovascular consequences of cortisol excess. Vasc Health Risk Manag. 2005; 1(4): 291-299, indexed in Pubmed: 17315601

44. Mains RE, Alam MR, Johnson RC, et al. Kalirin, a multifunctional PAM COOH-terminal domain interactor protein, affects cytoskeletal organization and ACTH secretion from AtT-20 cells. J Biol Chem. 1999; 274(5): 2929-2937, doi: 10.1074/jbc.274.5.2929, indexed in Pubmed: 9915831.

45. Omari N, Dahmani-AitAkli Y, Labrousse F, et al. Influence of the streptozotocin on the corticotrope axis of the Wistar rat (Rattus norvegicus). Bulletin de la Société Royale des Sciences de Liege. 2011; 80: 907-938. 
46. Wilke RA, Hillard CJ. Decreased adrenal medullary catecholamine release in spontaneously diabetic BB-Wistar rats. Role of hypoglycemia. Diabetes. 1994; 43(5): 724-729, doi: 10.2337/ /diabetes.43.5.724.

47. Gallego M, Setien R, Izquierdo MJ, et al. Diabetes induced biochemical changes in central and periphery catecholaminergic systemes. Physiol Res. 2003; 52: 735-741, indexed in Pubmed: 14640895.

48. Omari N, Ait-Akli D, Haffaf M, et al. L'axe adrenocorticotrope et le stress chez le rat des sables (Psammomys obesus). Le pharmacien d'Afrique. 2007; 198: 8-19.

49. Olukole S, Adeagbo M, Oke B. Histology and histochemistry of the adrenal gland African Giant Rat (Cricetomys gambianus, Waterhouse). Int J Morphol. 2016; 34(4): 1455-1460, doi: $10.4067 / \mathrm{s} 0717-95022016000400045$.

50. Sricharoenvej S, Boonprasop S, Lanlua P, et al. Morphological and microvascular changes of the adrenal glands in streptozotocin-induced long-term diabetic rats. Ital J Anat Embryol. 2009; 114(1): 1-10, indexed in Pubmed: 19845276.

51. Jainu M, Devi S. In vitro and in vivo evaluation of free radical scavenging potential of Cissus quadrangularis. Afr J Biomed Res. 2005; 8: 95-99.
52. Halliwell B, Cross CE. Oxygen-derived species: their relation to human disease and environmental stress. Environ Health Perspect. 1994; 102(Suppl 10): 5-12, indexed in Pubmed: 7705305.

53. Abdel-Aziz HO, Ahmed SA. Curcumin protection against nicotine induced histological changes of the chromaffin cells of adrenal medulla in mice. J Am Sci. 2011; 7(9): 698-703 .

54. Galaly S, Hozayen W, Amin K, et al. Effects of Orlistat and herbal mixture extract on brain, testes functions and oxidative stress biomarkers in a rat model of high fat diet. Beni-Suef University Journal of Basic and Applied Sciences. 2014; 3(2): 93-105, doi: 10.1016/j.bjbas.2014.05.002.

55. Ueha S, Shand FHW, Matsushima K. Cellular and molecular mechanisms of chronic inflammation-associated organ fibrosis. Front Immunol. 2012; 3: 71, doi: 10.3389/fimmu.2012.00071, indexed in Pubmed: 22566952.

56. Jaleel CA, Gopi R, Manivannan P, et al. Antioxidant potential and indole alkaloid profile variations with water deficits along different parts of two varieties of Catharanthus roseus. Colloids Surf B Biointerfaces. 2008; 62(2): 312-318, doi: 10.1016/j. colsurfb.2007.10.013, indexed in Pubmed: 18068339.

Submitted: 8 July, 2016

Accepted after reviews: 4 July, 2017 Available as AoP: 6 July, 2017 